\title{
Where Buddhism Encounters Entertainment Computing
}

\author{
Daisuke Uriu ${ }^{1}$, Naohito Okude ${ }^{1}$, Masahiko Inami ${ }^{1}$, \\ Takafumi Taketomi ${ }^{2}$, and Chihiro Sato ${ }^{1}$ \\ 1 Graduate School of Media Design, Keio University \\ 4-1-1 Hiyoshi, Kohoku-ku, Yokohama, Japan 223-8526 \\ \{uriu, okude, inami, chihiro\}@kmd.keio.ac.jp \\ 2 Graduate School of Information Science, \\ Nara Institute of Science and Technology \\ 8916-5 Takayama, Ikoma, Nara, Japan 630-0192 \\ takafumi-t@is.naist.jp
}

\begin{abstract}
This special panel session provides an opportunity to discuss how entertainment computing designers create interactive media/ contents on Buddhism and also other religious practices. In this year, we have launched an exciting project designing interactive contents to be used in Todaiji temple, one of the world heritages located in Nara, Japan. In this project, we are actually collaborating with monks of the Todaiji temple, learning Buddhist rituals in this temple from the monks, and creating Augmented Reality contents working on high performance network infrastructure. This session consists of a presentation introducing our Todaiji temple project and a set of short key notes from specialists; researchers on Augmented Reality, Entertainment Computing, and Anthropology.
\end{abstract}

\section{Introduction}

Todaiji temple, registered as a world heritage, is one of most famous Japanese Buddhist temple. Its Buddhism religion - called Kegon-kyo, the Avatamsaka Sutra, or Flower Ornament Scripture [1-has been carried out over 1200 years. The Great Buddha of this temple (Right of Figure 1) is said to represent the world of Kegon-kyo and known as symbolic object for sightseers. In every February, the temple holds a special ritual ceremony called Shunie or Omizutori at Nigatsu-do Hall of this temple in two weeks. Monks run around the hall's balconies, swinging large torches (Left of Figure 1). This event continuing for over 1200 years owns very important meanings for the monks and has been attracting many visitors who believe being touched by the falling sparks can make them happy.

Fortunately, we-Nara Institute of Science and Technology (NAIST) 11 and Graduate School of Media Design, Keio University (KMD) 2 have acquired a

1 http://www.naist.jp/en/

2 http://www.kmd.keio.ac.jp/en/

A. Nijholt, T. Romão, and D. Reidsma (Eds.): ACE 2012, LNCS 7624, pp. 589-592, 2012.

(C) Springer-Verlag Berlin Heidelberg 2012 

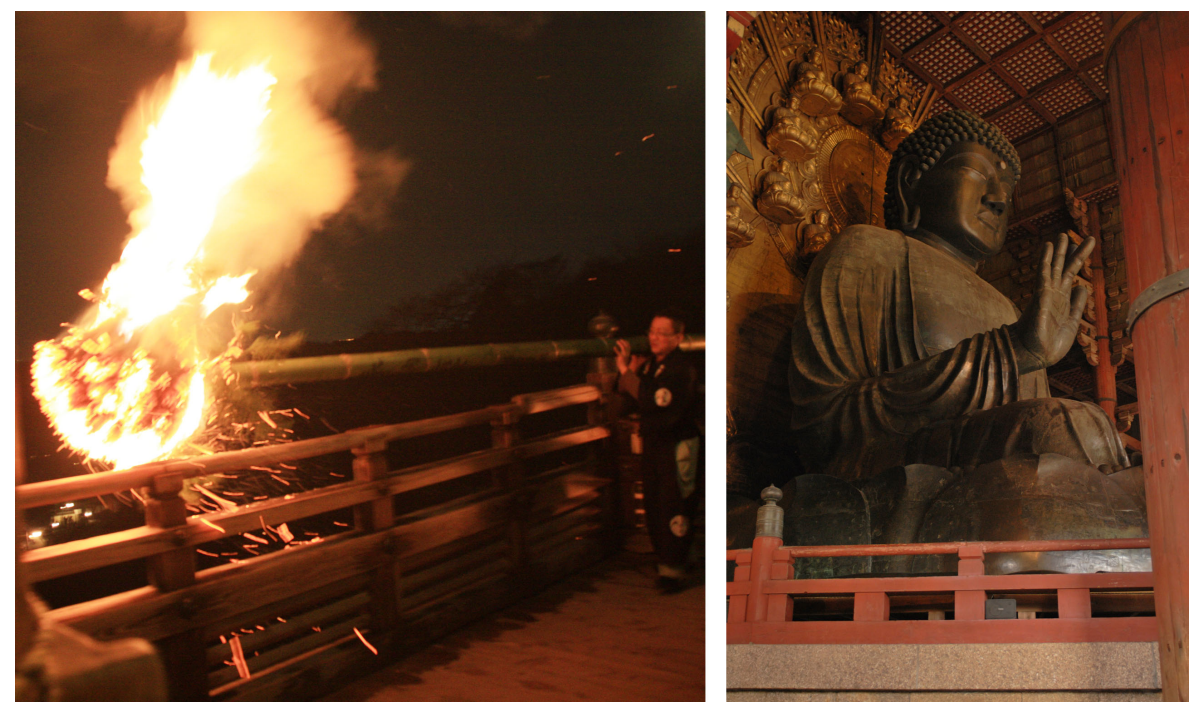

Fig. 1. Left: A monk runs with swinging the torche, Right: Great Buddha of the Todaiji temple

chance to collaborate with the Todaiji temple to conduct an exciting project designing interactive contents enabling students, the visitors, and the monks to learn about Todaiji and its difficult religion Kegon-kyo with walking around locations in the temple. Our initial purpose is to create Augmented Reality contents working on high performance network infrastructure, which is a challenge to design a novel experience, honestly even we have not imagined yet, crossing between human's spirituality, religious rituals, and cutting edge technologies.

Our design and development team of this project consists of researchers working on Anthropology, Augmented Reality, and Entertainment Computing. Naohito Okude, a professor in KMD, is investigating rituals of Kegonkyo and practices in the Todaiji temple based on anthropological studies. Masahiko Inami, a professor in KMD, is one of pioneers of Entertainment Computing. Takafumi Taketomi, an assistant professor in NAIST, specializes in the field of Augmented Reality. The team of this project has been discussing with the monks in Todaiji temple many times and now constructing specific contents to be used at the sites in the temple.

At the ACE 2012 conference, we organize a special panel session that provides an opportunity to discuss how entertainment computing designers create interactive media/contents on Buddhism and also other religious practices. Firstly we introduce our Todaiji temple project as a case study of designing digital contents supporting to learn Buddhist rituals. Panelists that come from our design team provide a set of short key notes from each of their specialized backgrounds. After the short key notes, the panelists discuss future forecasts for entertainment computing with religious practices; where Buddhism encounters entertainment computing, how interactive technologies should support humans spirituality, and what are the challenges to develop these interactive contents. 


\section{Spirituality HCI Supported}

An anthropologist Genevieve Bell firstly revealed connections between spiritual (especially religious) practices and technologies reviewing case examples from online virtual cemeteries to special mobile phone supporting religious practices at Ubicomp2006 conference 2. After her result, some researchers have been striving to design interactive digital media supporting spiritual practices, but there is still not many design oriented works yet. For example, Wyche produced an image based mobile phone application supporting Islam practices [3. While, Gaver designed a special physical artifact supporting nuns working at a church [4.

Our Todaiji temple project also challenges to design connections between one's spirituality and technologies, especially focusing on user experience when users - students, visitors, and young monks - walk around real locations in the temple. Our current purpose or goal in this project is to give them learnings of not only actions of rituals such as Omizutori but also strict meanings of Kegonkyo hidden from superficial ones. Our research approach, collaborating with the monks to design contents that extends ones' experience at physical locations at the temple, will provide a forecast how HCI researchers produce contents and media for supporting people's techno-spiritual practices [2].

\section{$3 \quad$ Moderator and Panelists}

\subsection{Daisuke Uriu (Moderator)}

He is an interaction designer especially focusing on connection between one's spiritual practices and memories. His recent work "Thanato Fenestra" [5] supports Buddhist rituals to pray for the repose of the dead persons' spirits with applying candle movements to effect digital photos. In the Todaiji temple project, he is producing to develop interaction design between physical objects in the temple and religious experience of Kegon-kyo.

\subsection{Naohito Okude}

He conducts some research projects related with cultural anthropology, phenomenology, media environment. He produced a Virtual Reality content reproducing Sistine Chapel located in Vatican in 1998. In the Todaiji temple project, he is trying to design spiritual experience packaged in on-site digital application, considering religious meanings of Kegon-kyo with employing his anthropological background.

\subsection{Masahiko Inami}

He is a scientist specializing in interactive technologies such as robotics, Virtual Reality, Augmented Reality, and Entertainment Computing. In the Todaiji temple project, he is the chief technology organizer utilizing multiple technologies and bridging them to the field of spiritual experience. 


\subsection{Takafumi Taketomi}

Takafumi Taketomi (Panelist) is developing a feature landmark based camera pose estimation method. In the Todaiji Project, he is working on vision-based markerless geometric registration outdoors. By using a structure-from motion, $3 \mathrm{D}$ structure of the target environment is automatically acquired.

\section{Contents}

This special session consists of 4 sections.

- Introduction about Todaiji temple and Todaiji temple project (20 min.)

- Panelists' talks (30min.)

- Discussion between panelists (20 min.)

- Discussion with the audiences (20 min.)

At first we will introduce Todaiji-temple and outline of our project. Secondly, each panelists will give the audiences a short talk related with his research background. Thirdly, panelists will discuss future forecasts for entertainment computing with religious practices. Finally, we reserve time to discuss the topics the panelists provide with the audience and conclude "Where Buddhism Encounters Entertainment Computing," how interactive technologies should support humans spirituality and religious experience, and what are the challenges to produce interactive contents supporting this issue.

Acknowledgments. This panel session is granted by NAIST Advanced Research Partnership Project.

\section{References}

1. Cleary, T.: The Flower Ornament Scripture: A Translation of the Avatamsaka Sutra. Shambhala (1993)

2. Bell, G.: No More SMS from Jesus: Ubicomp, Religion and Techno-spiritual Practices. In: Dourish, P., Friday, A. (eds.) UbiComp 2006. LNCS, vol. 4206, pp. 141-158. Springer, Heidelberg (2006)

3. Wyche, S.P., Caine, K.E., Davison, B.K., Patel, S.N., Arteaga, M., Grinter, R.E.: Sacred imagery in techno-spiritual design. In: Proc. of CHI 2009, pp. 55-58 (2009)

4. Gaver, W., Blythe, M., Boucher, A., Jarvis, N., Bowers, J., Wright, P.: The prayer companion: openness and specificity, materiality and spirituality. In: Proc. of CHI 2010, pp. 2055-2064 (2010)

5. Uriu, D., Okude, N.: Thanatofenestra: photographic family altar supporting a ritual to pray for the deceased. In: Proc. of DIS 2010, pp. 422-425 (2010) 